\title{
DEVELOPMENT AND DEMONSTRATION OF THE USE OF MODULAR THERMO-MECHANICAL PULPMILL SIMULATION MODELS TO DEVELOP ENERGY REDUCTION STRATEGIES DE92 000971 REPORT ONE
}

WORK PERFORMED UNDER CONTRACT NO. DE-GF02-90CE40937

THE INSTITUTE OF PAPER SCIENCE AND TECHNOLOGY ATLANTA, GEORGIA

PROJECT NO. 3704

PREPARED FOR:

KEITH ADKINS

CONTRACT SPECIALIST

AUGUST 15, 1991

\section{MASTER}


$\begin{array}{lll}\text { EXECUTIVE SUMMARY } & 1\end{array}$

BACKGROUND 3

$\begin{array}{lll}\text { PROJECT DESCRIPTION } & 4\end{array}$

STEADY STATE MODEL $\quad 4$

Data Reconciliation 5

"What If" Scenarios 5

optimization Scenarios 5

DYNAMIC TMP MODEL - "LOOK AHEAD" SCENARIO 6

SYSTEM DESCRIPTION

$\begin{array}{ll}\text { SCOPE OF PROJECT } & 7\end{array}$

PROPOSED SCHEDULE $\quad 9$

$\begin{array}{ll}\text { RESOURCE COMMITIENT BY CANDIDATE MILL } & 10\end{array}$

ANTICIPATED PROJECT RESULTS AND DELIVERABLES 11

PRINCIPAL INVESTIGATORS $\quad 12$

DISCLAIMER

This report was prepared as an account of work sponsored by an agency of the United States Government. Neither the United States Goyernment nor any agency thereof, nor any of their employees, makes any warranty, express or implied, or assumes any legal liability or responsibility for the accuracy, completeness, or usefulness of any information, apparatus, product, or process disclosed, or represents that its use would not infringe privately owned rights. Reference herein to any specific commercial product, process, or service by trade name, trademark, manufacturer, or otherwise does not necessarily constitute or imply its endorsement, recommendation, or favoring by th: United States Government or any agency thereof. The views and opinions of authors expressed herein do not necessarily state or reflect those of the United States Government or any agency thereof. 
DEVELOPMENT AND DEMONSTRATION OF THE USE OF MODULAR THERMOMECHANICAL PULPMILL SIMULATION MODELS TO DEVELOP ENERGY REDUCTION STRATEGIES

\section{EXECUTIVE SUMMARY}

The Institute of Paper Science and Technology (IPST) has received a project grant (hereinafter referred to as "The Project") from the U. S. Department of Energy (DOE) to develop and demonstrate the use of realtime process simulation modeling as a means of process analysis and optimization. The project, to be conducted under the auspices of the International Energy Agency (IEA), will target a Thermo-Mechanical pulping (TMP) operation as the site for the commercial implementation of the technology.

The American Paper Institute statistics for wood pulp forecast that 3.669 million tons of Thermo-Mechanical Pulp (TMP) will be produced in the United States in 1991 and that production will continue to expand by approximately 8 of per year. Typical energy calculations for the TMP process indicate that the energy required to produce TMP is approximately $3.58 \times 10^{3} \mathrm{kWh} /$ ton $(12$ million BTU/ton), making the total energy consumed approximately $1.314 \times 10^{10} \mathrm{kWh}\left(4.4 \times 10^{13}\right.$ BTU's) in 1991. Using an equivalent cost of 4.5 cents/kWh, the cost of such energy consumption in 1991 will be approximately $\$ 592,000,000$.

IPST and a sub-contractor, SACDA Inc. (SACDA), will cooperate in a two-to-three year effort to produce an on-line simulation program having both steady-state and dynamic modeling capabilities. The project will take advantage of a current IPST and SACDA joint development effort to merge the IPST's MAPPS (Modular Analysis of pulp and Paper Systems) program with SACDA's MASSBAL program. Using the combined proprietary programs, "realtime" steady-state and dynamic TMP models will be developed and installed as part of a "millwide" information/ analysis system. By utilizing the Performance Attribute (PAT) Modeling concept developed at IPST, the models will have the capability of optimizing energy usage and other process operating variables as a function of pulp quality.

The primary goal of the Project is to demonstrate that on-line simulation models can provide assistance to operators and managers in day-to-day operations. By embedding simulation analysis techniques such as data reconciliation and "what if," optimization, and "look ahead" scenarios within the program executive, timely process data and information, not otherwise available, will be provided to the operator. Such data and information can be used by the operator for process analysis, optimization and planning and/or to provide setpoints for open or closed loop advanced control strategies. 
The TMP Models, and the hardware/software systems required to develop them, will become a permanent part of the Candidate Mill's millwide system. More importantly, approximately one-third of the IPST/SACDA human resources allocated to the project will be used to develop and present process analysis and optimization studies which are expected to be extremely beneficial to the Candidate Mill. If the Project demonstrates even a small decrease in energy consumption, a substantial operating cost savings can be realized. For instance, a 1 \% energy usage reduction in a TMP pulpmill producing 1000 tons/day could result in a savings of $1.253 \times 10^{7} \mathrm{kWh} /$ year $\left(4.2 \times 10^{10}\right.$ BTU/year). At a cost of 4.5 cents/kWh for electrical energy, the cost savings over a 360-day year would be $\$ 580,000$.

The Project began in mid-April of 1991 and, assuming the promised DOE funding continues as expected, is scheduled for completion in October of 1993 (see included detailed schedule). The hardware/ software systems and the human resources required for their development and installation will be provided by IPST and SACDA and will be funded by the DOE, at no cost to the Candidate Mill.

However, it will be necessary for the Candidate Mill to provide the human resources, as required, to assist IPST/SACDA in the development and implementation of the project. It is anticipated that such assistance will primarily be directed toward (1) providing process design, operating, and quality data to build and validate the TMP process models; (2) providing the process control/ information system design and configuration data to integrate the developed system into the millwide system at the mill; and (3) assisting IPST/SACDA with the implementation of the system at the mill.

To conform with the terms of the DOE grant contract, the Candidate Mill must agree to release the general mill data (not proprietary data or data considered to be a part of the mill's competitive advantage) necessary to describe the findings of the project in a report. This final project Report will be distributed in the public domain by the DOE. In addition, the Candidate Mill will be asked by DOE to permit Project Reviewers and other industry representative to visit the mill to see the completed system. The details of these requirements will be negotiated with the Candidate Mill and, llong with this proposal, become a part of a definitive agreement $v$ de executed between IPST and the candidate Mill. 


\section{BACKGROUND}

Process simulation techniques have traditionally been used by researchers and engineers in an "off-line" mode to calculate material and energy flows for continuous industrial processes such as those for the production of pulp and paper. The resulting information was then utilized to design, de-bottleneck, troubleshoot and optimize pulp and paper process systems. With few exceptions, the simulation software resided on mainframe or micro computers remote from the "real" processes and design data and/or average mill data was used to set up the process models.

Although off-line simulation applications serve a valuable function, they often do not include the process operators and their managers. These individuals must constantly strive to optimize a process while producing a product of acceptable quality, a task requiring more data and information

than is usually available. A process simulation program having the ability to link material and energy flows with product quality could be useful to operators and managers for on-line process analysis applications.

The Institute of Paper Science and Technology, managed by a governing body composed of paper industry and related equipment, instrument, and process control systems manufacturers, has research programs which focus on the needs of the industry. This focus led to the research efforts which resulted in the development of MAPPS, a simulation program created on the foundation of the extensive engineering, research, and educational resources of the Institute.

MAPPS has the capability of modelling material and energy flows for mechanical pulping, chemical pulping, bleaching, papermaking, chemical recovery, and steam-and-power operations and has been licensed by numerous pulp and paper companies in North America and elsewhere. Most recently, the continuing development of MAPPS has given the program the capability of predicting pulp and paper quality parameters, a feature referred to as Performance Attribute (PAT) Modeling.

SACDA markets a number of process simulation programs on a worldwide basis, notably MASSBAL MK I and II (steady state) and TRAINER and DESIGNER (dynamic). Most recently, SACDA announced the release of a new program, MASSBAL 3, which can run both steady state and dynamic process models.

The programs and resources of IPST and SACDA will be combined to develop and implement this Project. 


\section{PROJECT DESCRIPTION}

The Institute of Paper Science and Technology is the principal center of cooperative research for the pulp and paper industry in the United States. Using the Institute's considerable engineering, research, and educational resources, MAPPS (Modular Analysis of pulp and paper systems), a steady-state simulation program was developed. In addition to calculating material and energy flows for all of the streams in a process, MAPPS can also calculate product quality parameters such as Canadian standard Freeness (CSF), burst, tear, tensile, brightness, etc. The process and utility modules developed for the current steady state version of MAPPS will be used in the modeling of a TMP pulpmill for the Project.

SACDA Inc., a Canadian company located in London, ontario has demonstrated world-wide expertise in the development of dynamic simulators for pulp and paper operations, including TMP pulping. SACDA will integrate the appropriate MAPPS process and utility modules into MASSBAL 3 to create a combined program with both steady state and dynamic capabilities. SACDA will also develop the on-line executive software and a software interface for the selected mill's distributed control system and be responsible for the transportation, instaliation, and testing of the completed simulation system at the mill site.

The Project will thus combine the best features of MAPPS and MASSBAL 3 to create on-line steady state and dynamic TMP Models that can be used for optimizing energy usage and other process operating variables as a function of product quality. Utilizing the simultaneous solution technique of MASSBAL 3 , these models can easily be used for process data reconciliation and can be constrained to simulate optimal solutions of existing or "what if" conditions.

In a cooperative effort with the Candidate Mill's technical and operating personnel, IPST will collect the data required to set up and validate the steady state and dynamic models off site. Before and after installation of the system at the mill, both SACDA and IPST will work with the mill's personnel to develop techniques for use of the modeling system on a realtime basis. As a starting point for this effort, the following uses of the develored models are suggested:

\section{STEADY STATE TMP MODEL}

Using the concept of perfect process equilibrium (no changes), a steady state TMP simulation model can predict material and energy flowrates for any process location as well as many operating and quality parameters (examples: refining consistency and tear, respectively). Conversely, for the real process, many of these 
flowrates and parameters either cannot or have not been measured. In addition, certain process flows or parameters (example: stock flows and consistencies) may be inaccurately measured and tested quality data such as CSF, tear, burst, etc., may not be available on a timely basis.

Thus, several simulation modes can be developed to provide timely and useful data and information to the operator or manager. It should be noted that the first of these modes, data reconciliation, must be implemented before the remaining modes can be effectively utilized.

1. Data Reconciliation. Measured process flowrates and parameters that are in error will not satisfy the fundamental mass and energy balance for the process. The extent to which the data deviates from the balance, i.e., the internal inconsistency of the data, is a measure of its inaccuracy. Data reconciliation can be an effective tool for providing frequent, accurate, and consistent "best estimates" of operating data.

To accomplish data reconciliation, selected realtime process measurements from the DCS or IS will be used to initialize a simulation model. The calculated results from the model will be compared with all of the available process measurements. A routine will then be then initiated to construct a "best fit" to minimize the differences between the process measurements and calculated values to form the "hest estimate" of the operating data.

Data reconciliation can be used t:o (1) validate actual instrument readings, (2) estimate process dilta that is not measured or is not available due to instrument nalfunctions, and (3) provide a validated set of pertinent process data to the mill's is for management reporting or for the implementation of advanced control strategias.

2. "What If" Scenarios. Upon rompletion of the data reconciliation mode, a validated process model will be available as the "base case" for comparative "what if" studies. Any number of pre-defined scenarios can be set up for the operator or manager to consider. In addition, a generic scenario can be set up for special cases the operator/manager may wish to define. Example scenarios could be (1) production rate changes, (2) shut down or startup of one or more lines, (3) changes in energy usage strategy, (4) changes in pulp properties, and (5) changes in the set up of screening, cleaning, and reject handing systems.

3. Optimization Scenarios. Again, starting from the validated process model, optimization scenarios can be set up for the operator. For a multi-line TMP operation with complex screening, cleaning, and reject handling systems, true process optimization 
setups are difficult to attain without computerized assistance. By taking advantage of MASSBAL $3^{\prime} \mathrm{s}$ non-linear programming capability, pre-defined optimization scenarios can be conceived in which an objective function is optimized. Examples of such scenarios are:

(1) Minimize primary/secondary refiner energy constrained by product quality standards;

(2) Minimize total energy usage constrained by product quality and/or reject generation;

(3) Optimize energy usage for variable chip characteristics constrained by product quality and/or reject generation;

(4) Minimize total energy usage constrained by screeriing reject rates.

\section{DYNAMIC TMP MODEL - "LOOK AHEAD" SCENARIO}

A dynamic model will be set up to emulate the "real" TMP operation and, in addition to equipment models, will include process control elements, piping systems, and storage tanks and other process holdups. The concept for the dynamic model is that it will be initialized by the validated steady state model discussed above and will have the capability of running faster than realtime. Thus, starting from the present, the operator or manager can "look ahead" to see what will happen if the current process setpoints are maintained.

To the knowledge of the IPST/SACDA personnel participating on the project, there are presently no examples to draw from in setting up a realistic "look ahead" scenario. During the course of the Project, IPST and SACDA will work with the Candidate Mill's personnel to develop this scenario. Potentially, the dynamic model could be used to (1) predict the future time impact of current operating parameters and TMP quality on the pulp being sent to the paper mill and (2) predict the future time and quality impact that changes in the current operating setup will have on pulp sent to the paper mill.

\section{SYSTEM DESCRIPTION}

The MAPPS/MASSBAL 3 software and the TMP models will be developed for delivery to the Candidate Mill on a VAxstation 3100 Model 76 hardware platform. The system, as illustrated in Figure 1 , will be configured to be extremely "user friendly" for the operator. A brief description of the individual elements follows. 


\section{SIMVIEW}

SIMVIEW, the simulation executive, will also serve as the operator interface. It will be based on a third party graphical configuration program. Thus, the "user front end" can actually be a graphical reproduction, or an enhancement, of the TMP graphical displays from the DCS. All of the simulation modes discussed above will be set up using $\mathrm{x}$-windows and can be accessed using a mouse-driven cursor. Normal language prompts (not simulation-related keywords) will be used to guide the operator through each of the simulation modes.

\section{SIMULATION DATABASE}

A simulation database will be set up to manipulate the realtime process data from the DCS or IS and to store the simulation input and output files. From this database, realtime process data inputs will be read into the simulation input and predicted results from the simulation output will be written back to the DCS or IS database as required.

MODEL BUILDER

The MODEL BUILDER will be a graphics based, keyword driven program that can be used by a process/process control engineer to build new simulation input files or modify existing files. However, the operator will not need to access the MODEL BUILDER, to run any of thr simulation modes discussed earlier.

DCS/IS INTERFACE

The DCS/IS Interface will transfer data to and from the DCS or IS. It will be custom designed to access realtime process data from its normal storage location and to send calculated data back to a specified DCS or IS database location as required.

\section{SCOPE OF THE PROJECT}

The scope of the Project, broken down into the tasks presented in the original funding proposal to the DOE, is listed below. Based on the assumption that the promised DOE funding will continue as scheduled, the project will be carried out over a period of 2.5 years. However, if the funding for the project can be accelerated, an earlier completion date may be possible. 


\section{APRIL 1, 1991 - SEPTEMBER 30, 1992}

TASK A - Project Planning and review with DOE/IEA - (OFF SITE) IPST - 6 mandays

SACDA - 2 mandays

Task B - Modification of the MASSBAL 3 software to incorporate the required MAPPS process and utility modules (OFF SITE)

IPST - 20 mandays

SACDA - 59 mandays

Task C - Development of the on-line executive (OFF SITE)

SACDA - 25 mandays

Task D - Development of the interface for the mill's DCS and/or IS - (OFF SITE)

SACDA - 15 mandays

Task E - Collection and analysis of the required mill data to set up, tune, and test the initial model of the mill's TMP pulping process - (OFF SITE)

IPST - 10 mandays

Task F - Modeling of the TMP Mill and system integration - (OFF SITE)

IPST - 20 mandays

SACDA - 20 mandays

Task G - Testing and tuning of TMP model (OFF SITE)

IPST - 40 mandays

SACDA - 15 mandays 
OCTOBER 1, 1992 - SEPTEMBER 30, 1993

Task $\mathrm{H}$ - on-site installation, testing, and tuning

IPST - 25 mandays

SACDA - 15 mandays

Task I - on-site analytical and optimization studies and writing of final report for DOE/IEA

IPST - 60 mandays

\section{PROPOSED SCHEDULE}

A detailed schedule, keyed to the Tasks listed above, has been compiled by IPST and SACDA and is summarized below:

COMPLETION TASK DESCRIPTION BY

DATE

$5 / 1 / 91$

$6 / 1 / 91$

$8 / 1 / 91$

$8 / 1 / 91$

$8 / 1 / 91$

$9 / 1 / 91$

$9 / 1 / 91$

$10 / 1 / 91$

$12 / 1 / 91$

$1 / 1 / 92$

$2 / 1 / 92$
A

$-$

$-$

E

$\mathbf{B}_{1}$

$c_{1}$

$\mathrm{D}_{1}$

$c_{2}$

$\mathrm{B}_{2}$

$F_{1}$

$\mathbf{F}_{2}$
PLANNING MEETING

SPEC. OF HARDWARE

PURCH. \& DEL. HDWR.

COLLECT INITIAL PROC. INFO.

$$
\begin{array}{lll}
\text { DESIGN \& OP. DATA } & \text { HOST/IPST } \\
\text { SELECT MODES FOR SIM. } & \text { HOST/IPST }
\end{array}
$$

DEV. PATS INT. STRATEGY IPST/SACDA

SPEC. OF EXECUTIVE

SPEC. OF INTERFACE

DESIGN OF DATABASE

MAPPS/MASSBAL INT.

BASIC MASSBAL CONFIG

DETAIL MASSBAL CONFIG
HOST/IPST/SACDA HOST/SACDA

HOST/IPST/SACDA

IPST/SACDA

SACDA

SACDA 


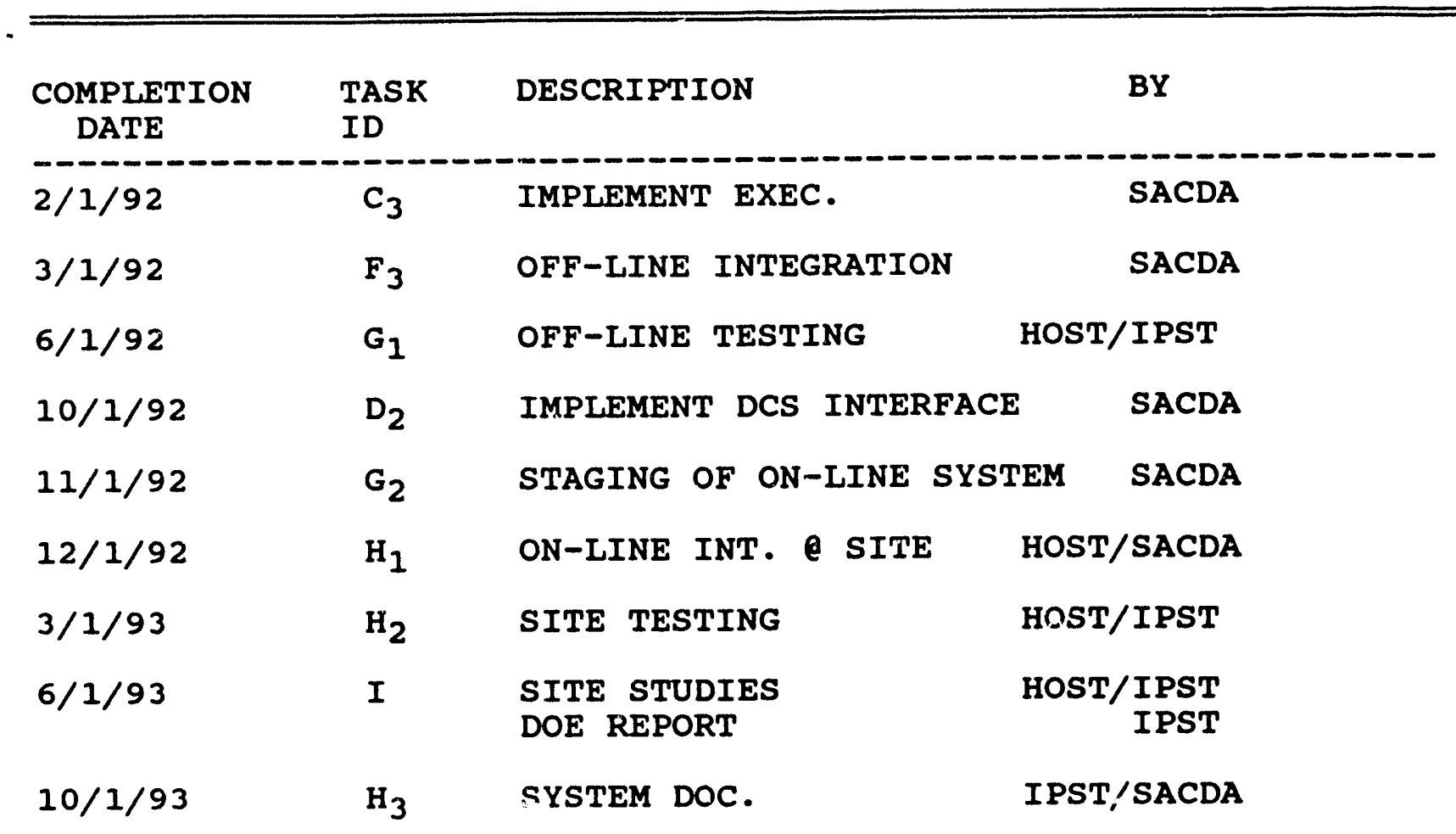

\section{RESOURCE COMMITTMENT BY CANDIDATE MILL}

The Candidate Mill will be expected to provide the human resources, as required, to assist IPST and SACDA in the development and implementation of the project. It is anticipated that such assistance will consist of, but not necessarily be limited to, the following tasks:

(1) provide the process design, operating, and quality data required by IPST and SACDA to build and validate the TMP process models;

(2) provide the process control/information system design and configuration data required by IPST and SACDA to integrate the developed system into the millwide system at the mill;

(3) assist IPST and SACDA with the implementation of the system at the mill.

To conform with the terms of the LDE grant contract, the Candidate Mill must also agree to release the general mill data (not proprietary data or data considered to be a part of the mill's competitive advantage) necessary to describe the findings of the Project in a report. This final Project Report will be distributed in the public domain by the DOE. In addition, the Candidate Mill will be asked by DOE to permit Project Reviewers and other industry representative to visit the mill to see the completed system. The details of these requirments will be 
negotiated with the Candidate Mill and, along with this proposal, become a part of a definitive agreement to be executed between IPST and the candidate Mill.

\section{ANTICIPATED PROJECT RESULTS AND DELIVERABLES}

The Project was conceived and planned to demonstrate that on-line simulation models can provide assistance to operators and managers in the day-to-day planning and optimal operation of a process. The Data Reconciliation Mode provided with the System can be used to (1) validate actual instrument readings, (2) estimate process data that is not measured or is not available due to instrument malfunctions, and (3) provide a reconciled set of pertinsst process data to the mill's Is for management reporting or for the implementation of advanced control strategies.

Then, by using the other steady state simulation modes, i.e., "What If" and optimization Scenarios, parametric studies of appropriate sets of operating setpoints can be conducted to analyze alternative operating conditions or set up optimum operating conditions.

Finally, the dynamic modeling feature, the "Look Ahead" Scenario, has the potential of being used to (1) predict the future time impact of current operating parameters and TMP quality on the pulp being sent to the paper mill and (2) predict the future time and quality impact that changes in the current operating setup will have on pulp sent to the pajer mill.

The predicted process and quality data from these simulation modes will also be available to the operator for process control purposes. Such data can be used to improve open loop control techniques now used by the operator or to develop higher level advanced control strategies to "close the loop."

The TMP Models, and the hardware/software systems required to develop them, will become a permanent part of the Candidate Mill's millwide system. More importantly, approximately one-third of the IPST/SACDA human resources allocated to the project will be used to develop and present process analysis and optimization studies which are expected to be extremely

beneficial to the Candidate Mill. For instance, if the project produces a system that only results in a small decrease in energy consumption, a substantial operating cost savings will be realized. It is estimated that a 1 \& energy usage reduction in a TMP pulpmill producing 1000 tons/day will produce a savings of $1.253 \times 10^{7} \mathrm{kWh} /$ year $\left(4.2 \times 10^{10} \mathrm{BTU} /\right.$ year $)$, a potential savings of $\$ 580,000 /$ year over a 360-day year (using an electrical cost of 4.5 cents/kwh). 


\section{PRINCIPAL INVESTIGATORS}

\section{James D. Rushton - IPST}

The Principal Investigator at IPST for the proposed zontract will be Dr. James D. Rushton, Associate Professor and Group Leader for Process Simulation and Control in the Engineering and Paper Materials Division. Dr. Rushton has worked in the pulp and paper industry for 27 years and, prior to joining IPST, was Durector of Process Technology for Bowater Incorporated. His research expertise involves all phases of pulp and papermaking and he has extensive experience in the use of simulation techniques for process design and analysis.

Dr. Gary L. Jones - IPST.

Dr. Gary L. Jones is an Associate Professor and a Senior Research Associate in the Engineering and Paper Materials Division at IPST. He is the principal developer of the Performance Attribute (PAT) Modeling feature of MAPPS and has written and presented numerous technical papers dealing with PAT Modeling. His research expertise includes process simulation, process control, numerical techniques, paper physics, mechanical pulping and papermaking.

\section{Mr. Eric L. Leaver - SACDA}

The Principal Investigator for SACDA Inc. will be Mr. Eric $W$. Leaver, Director of SACDA Inc. Mr. Leaver has been associated with the world-wide pulp and paper industry for many years and is a known expert in the area of process control and simulation. Prior to his association with SACDA Inc., he was a principal in one of the largest Canadian process control-related companies.

Dr. William Morton - SACDA

Dr. Morton is Manager, Simulation Technology for SACDA Inc. and is an expert in both steady-state and dynamic simulation technology. Prior to joining SACDA, he was a University Professor and Supervisor of Advanced Simulation Research in the Department of Chemical Engineering at Cambridge University. For more than ten years, Dr. Morton has been actively engaged in research in process simulation, chemical reactors, particle physics, and mathematics and is the originator of the QUASIIIN Dynamic Process Simulation Package. During sabbatical leave and vacations from Cambridge, Dr. Morton was employed by such companies as B. P. International, Mobil Research and Development, and the Technical Research Centre of Finland. 

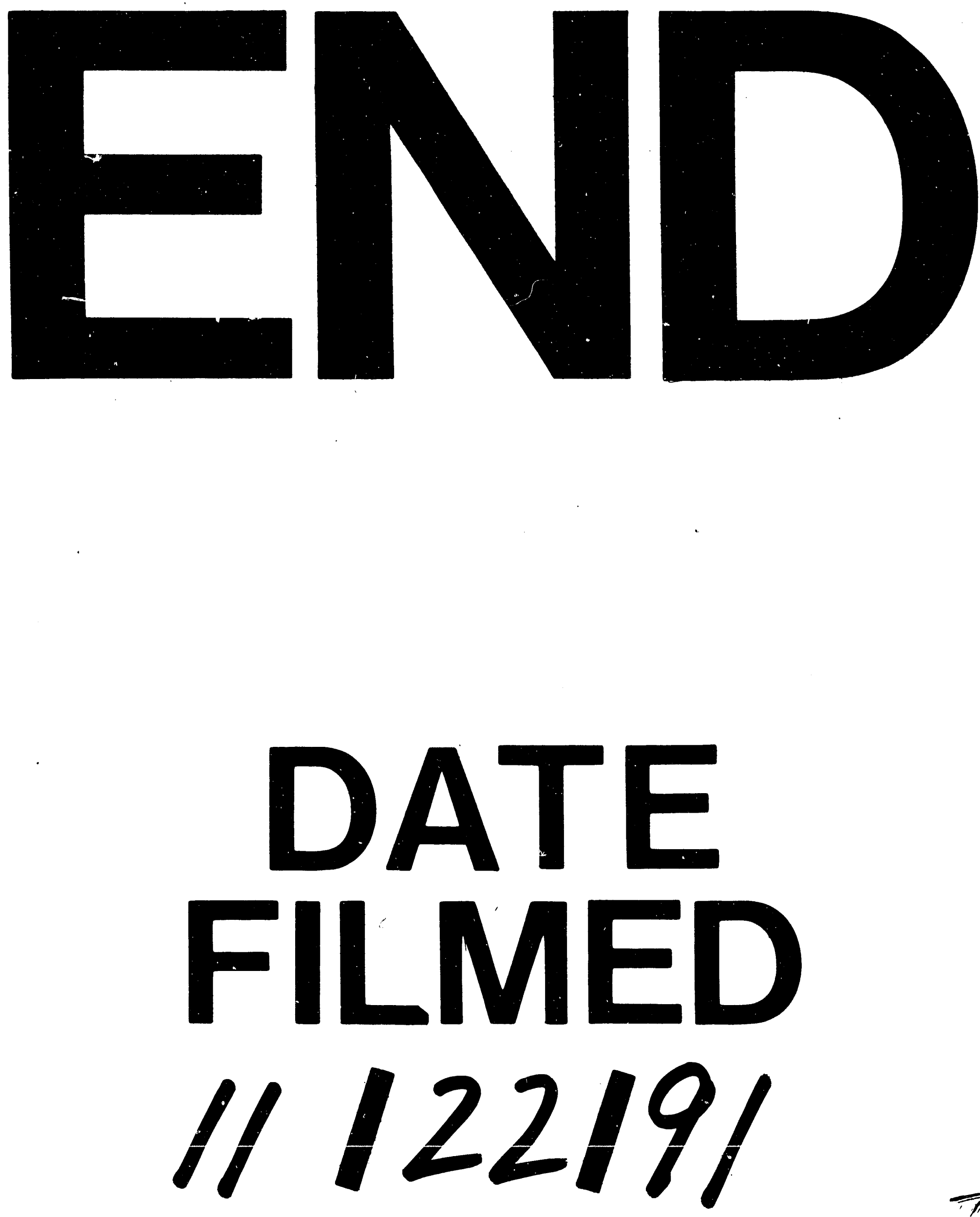
